\title{
Akıllı Ev Uygulamaları için Yeni Nesil IoT Denetleyici ile Gerçek Zamanlı Uzaktan İzleme ve Kontrol Uygulaması
}

\author{
Mehmet TASTTAN*1] \\ ${ }^{1}$ Manisa Celal Bayar Üniversitesi, Turgutlu Meslek Yüksekokulu, Elektronik ve Otomasyon Bölümü, 45400, \\ Turgutlu, Manisa
}

(Alınış / Received: 07.02.2019, Kabul / Accepted: 30.07.2019, Online Yayınlanma / Published Online: 30.08.2019)

Anahtar Kelimeler

IoT,

Blynk,

ESP32,

GPS,

Akıllı ev
Özet: İnternet çağını çok hızlı yaşadığımız günümüzde, sürekli olarak artan Nesnelerin İnterneti (IoT) uygulamaları hayatımızı kolaylaştırmaktadır. İnsan makine etkileşimli IoT tabanlı uygulamaların en popüleri şüphesiz akıllı ev uygulamalarıdır. Akıllı ev uygulamalarında cihazlar birbiri ile haberleşerek insan müdahalesi olmadan çalışabilirler. Buda bize zaman ve enerjiden tasarruf etmemizi sağlar. Bu çalışmada; 32-bit Dual Core ESP32 modül ve Blynk IOS/Android arayüz geliştiricisi kullanarak gerçek zamanlı veri izleme ve kontrol uygulaması gerçekleștirilmiștir. Blynk platformuyla tasarlanan Android tabanlı uzaktan izleme ve kontrol arayüzü sayesinde bir akıllı eve ait sıcaklık ve nem verileri kullanılarak ısıtma sisteminin kontrolü sağlanmıştır. Mobil cihaza kurulan android arayüz, ısıtma sisteminin çalışma saatlerini belirleyen haftalık programlama özelliğine sahiptir. Mobil cihazdan elde edilen konum bilgisi kullanılarak, ESP32 modül ile mobil cihaz arasındaki mesafe anlık olarak hesaplanır. Hesaplanan bu mesafeye göre ısıtma sistemi otomatik olarak çalışır veya durur. Blynk uygulamasının sunduğu bulut hizmeti, bize sistem ile ilgili sayısal verilerin depolama imkanını sunmaktadır. Önerilen IoT tabanlı bu akıllı ısıtma sistemi sağladığı enerji tasarrufunun yanında kullanıcıların konforunu da arttırmaktadır.

\section{Real Time Remote Monitoring and Control Application with New Generation IoT Controller for Smart Home Applications}

Keywords

IoT,

Blynk,

ESP32,

GPS,

Smart home

\begin{abstract}
In today's world where we live very fast, the continuously increasing Internet of Objects (IOT) applications make our life easier. The most popular of human-machine interactive IOT-based applications are undoubtedly smart home applications. In smart home applications, devices can work without human intervention by communicating with each other. It allows us to save time and energy. In this study; using the 32-bit Dual Core ESP32 module and the Blynk IOS / Android interface developer, real-time data monitoring and control has been implemented. The Android-based remote monitoring and control interface designed with the Blynk platform provides control of the heating system using temperature and humidity data from an intelligent home. The android interface installed on the mobile device has a weekly programming feature that determines the working hours of the heating system. Using the position information obtained from the mobile device, the distance between the ESP32 module and the mobile device is instantaneously calculated. The heating system automatically starts or stops according to the calculated distance. The cloud service provided by the Blynk application allows us to store system related digital data. The proposed IoT-based smart heating system not only saves energy but also improves the comfort of the users.
\end{abstract}

\section{Giriş}

Nesnelerin interneti fiziksel nesnelerin birbirleriyle veya daha büyük sistemlerle bağlantılı olduğu bir ekosistemdir [1]. Bu ağ, günlük hayatta kullandığımız çok farklı cihazlardan elde edilen milyarlarca veriyi toplayıp, kullanılabilir bilgilere dönüştürür. Teknoloji çağını yaşadığımız günümüzde kullandığımız birçok cihaz ve makine başta akıllı telefonlar ve tabletler olmak üzere farklı birimler ile uzak noktalardan rahatlıkla izlenebilmekte ve kontrol edilebilmektedir $[2,3]$. Gömülü sistem mikrodenetleyici üreten firma 
sayısının her geçen gün artmasıyla beraber bu ürünlerin fiyatları da hızla düşmektedir. Bununla beraber Android ve IOS arayüz geliștirme programlarının kullanıcı dostu haline gelmesiyle IoT ile birlikte akıllı uygulama örnekleri hızla artmaktadır [4,5]. Öngörülere göre, dünyada 2003 yılında birbiri ile etkileşimli olan 500 milyon cihaz varken, bugün 20 milyar cihaz seviyelerinde olduğu, bu rakamın 2020 yılına gelindiğinde 50 milyar cihaza çıkması tahmin edilmektedir [6]. Bu da gösteriyor ki, önümüzdeki yıllarda IoTile yaşadığımız şehirler, daha tempolu ve planlı yaşama ayak uyduran akıllı şehirler haline dönüşecektir. Bu dönüşüm beraberinde insan hayatını kolaylaştıran birçok fırsatı da bizlere sunacaktır. Kişisel ihtiyaçların hızla arttığı günümüzde, bu ihtiyaçları karşılama oranının oldukça yüksek olduğu şehir merkezlerine göç hızlanmaktadır. Dünya yeni bir döneme giriyor ve yakın gelecekte, dünya nüfusunun çoğunluğunun hayatlarını akıllı şehirlerde ve akıllı evlerde geçireceği öngörülmektedir [7]. $\mathrm{Bu}$ şehirlerde zorluklarla başa çlkmak, sürdürülebilir bir kentsel gelişmeyi desteklemek ve vatandaşların yaşam kalitesini iyileştirmek için çok disiplinli bir yaklaşıma ihtiyaç vardır [8]. Akıllı şehir, enerji kaynaklarını ve zamanı en iyi şekilde yöneterek yaşayanlarına, yüksek bir yașam kalitesi sağlayan sürdürülebilir ve verimli bir yerleşim merkezidir. Enerji yönetimi, enerji sistemlerinin karmaşıklığına ve yaşamsal rolüne bağlı olarak, bu tür kentsel merkezlerdeki en zorlu konulardan biridir [9]. Akıllı Ev, birbirleriyle iletişim kurabilen, aydınlatma, ısıtma, klima, TV, bilgisayar, eğlence, ses-görüntü sistemleri, güvenlik ve kamera sistemlerine sahip bir yaşam alanını tanımlamak için yaygın olarak kullanılan terimdir [10]. Ses ve görüntü sistemimizin eve girişimiz ile çalışması, aydınlatma ve elektrikli cihazların uzaktan kontrol edilebilmesi [11,12], Isitma sisteminin bölgesel hava durumuna göre ayarlarını otomatik olarak değiştirmesi [13], buzdolabı, klima, fırın gibi cihazların enerji tüketimlerinin izlenmesi ve kontrol edilmesi [14], bahçenizdeki sebzelerinizin sulanmasında zamanın değil toprağın neminin dikkate alınması [15], sürekli takip gerektiren sağlık problemleri yaşayan kişilerin giyilebilir medikal cihazlarla güvenilir bir yaşam sürmesi $[16,17]$, akıllı tarım uygulamaları [18], akıllı çevre, akıllı ulaşım, akıllı eğitim [19] gibi bir çok alanda hayatımızın kalitesi ve konforu arttıran IoT tabanlı teknoloji uygulamalarının sayısı her geçen gün katlanarak artmaktadır. Enerji ihtiyacımızın büyük bir bölümünü halen fosil yakıtlar ile sağladığımız günümüzde, eğer yenilenebilir enerji kaynaklarının toplam enerji tüketimindeki payı hızla arttırılmazsa yakın gelecekte küresel bir enerji darboğazına sürükleneceğimiz öngörülmektedir [20]. Enerjinin çok önemli olduğu günümüzde, yeni enerji kaynakları elde etmenin yanında, mevcut enerji kaynaklarının da maksimum verimle kullanılması büyük önem kazanmıștır. Konutlarda enerji tüketiminin büyük bölümünü oluşturan ısıtma, soğutma ve havalandırma gibi iklimlendirme sistemlerinde, kullanıcı konforuyla beraber enerji tüketiminin en aza indirilmesi ana hedefler arasındadır. [21]. Konut enerji tüketimi tüm sektörler içinde \%25'lik bir paya sahiptir. Bu tüketim değerinin \% 64'lük kısmı konutlardaki iklimlendirme sistemleri için kullanılmaktadır [22].

$\mathrm{Bu}$ çalışmada bir haneye ait ısıtma sisteminin enerji tüketimini azaltacak IoT tabanlı gerçek zamanlı izleme ve kontrolü önerilmiştir. Önerilen bu sistem için öncelikle Blynk platformu tarafından bir Android arayüz tasarlanmıştır. Daha sonra gömülü mimariye sahip ESP32 modül ile sistemin kontrolör birimi oluşturulmuştur. Dahili WiFi modüle sahip bu IoT denetleyicisi sayesinde kullanıcılar ısıtma sistemine ait tüm çalışma parametrelerine ulaşabilmekte ve sistemi programlayabilmektedir. Gerçek zamanlı olarak birden fazla kullanıcı tarafından kontrol edilebilen sistem WiFi ağ üzeriden kablosuz olarak kullanıcılar ile haberleşmektedir. Android kullanıcı arayüzü iç ortama ait sıcaklık ve nem bilgilerini kullanıcılara sayısal ve grafiksel veri olarak sunmaktadır. Ayrıca bu veriler Blynk bulut hizmeti sayesinde depolanmakta ve istenildiğinde bu verilere ulaşlabilmektedir. Android tabanlı bu akıllı ısıtma sisteminin GPS özelliği sayesinde, kullanıcıların tamamı haneyi terk ettiğinde sistem minimum tüketim sağlayacak ayar değerlerinde çalışmasını sürdürmektedir. Tersi durumda haneye olan uzaklık önceden belirlenen mesafeye düştüğünde ısıtma sistemi tekrar devreye girmektedir. Önerilen sistem enerji tüketimini azaltmanın yanında hane halkına ısı konforu da sağlamaktadır.

\section{Materyal ve Metot}

Gerçek zamanlı uzaktan izleme ve kontrol sistemi için, gömülü sistem mimari yapıya ve dahili WiFi modüle sahip Espressif firmasına ait ESP32 modül kullanılmıştır. IoT uygulamaları için özel geliştirilen bu 32 bitlik denetleyici, düşük maliyet ve yüksek performansa sahip olması nedeniyle çok tercih edilmektedir. Ortama ait sicaklık ve nem bilgileri, dijital yapısıyla yüksek doğruluğa sahip DHT22 sensörü tarafından alınmıştır. ESP32 çift çekirdekli yapısıyla akıllı ev uygulamaları için ihtiyaç duyulan WiFi, bluetooth, CAN, Ethernet, sıcaklık sensörü, manyetik alan sensörü ve touch sensör gibi bir çok gömülü özelliğe sahiptir.

Şekil 1'de pin yapısı görülen ESP32 modül 18x12 bitlik ADC ve 2x8 bitlik DAC pinlerine sahiptir. ESP32 bünyesinde, Harvard Tensilica Xtensa LX6 32 bit Dual Core, $240 \mathrm{MHz}$ frekansa kadar çalıșabilen bir ișlemci barındırır [23]. ESP32 modül ücretsiz olarak kullanılabilen $\mathrm{C}, \mathrm{C}++$ ve Lua gibi diller tarafından üzerinde bulunan mikro USB port sayesinde rahatlıkla programlanabilmektedir. Tablo 1'de bu denetleyiciye ait teknik özellikler görülmektedir. 


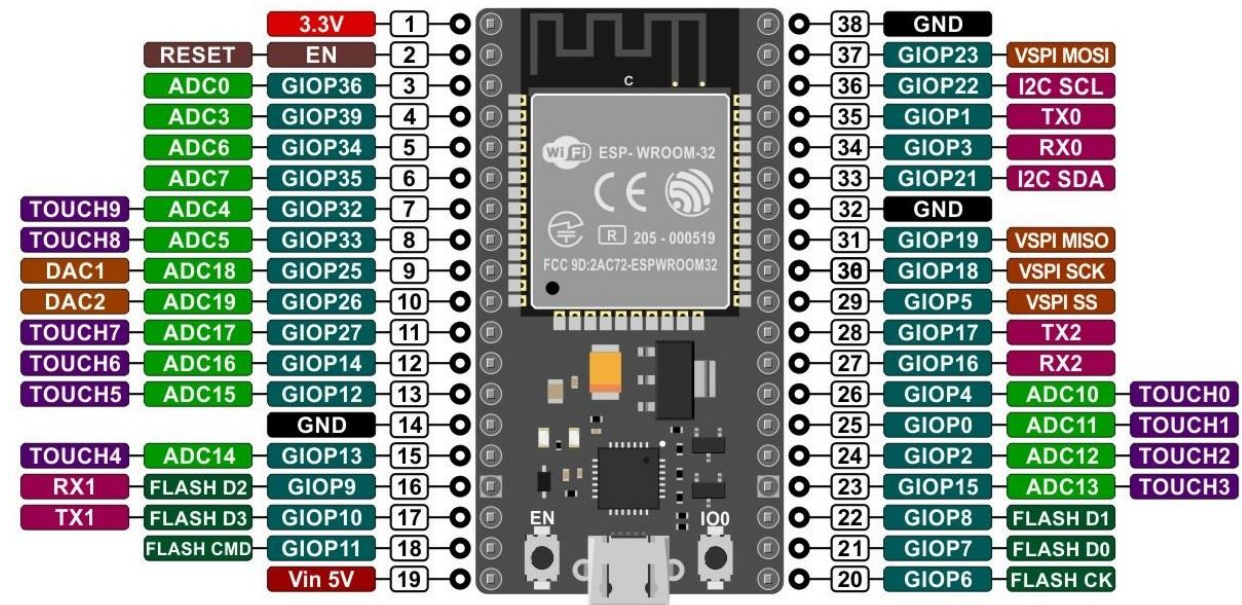

Şekil 1. ESP32 modülün pin yapısı.

Tablo 1. ESP32 modülün teknik özellikleri

\begin{tabular}{cc}
\hline Özellikler & ESP32 \\
\hline MCU & Tensilica Xtensa LX6 \\
Flash & 32 bit Dual Core, 240 MHz \\
Mimari & HarB \\
SRAM & $512 \mathrm{~KB}$ \\
Input/Output & $36 \times \mathrm{xDIO}$ \\
ADC Pin & $18 \times 12 \mathrm{bit}(1 \mathrm{~V})$ \\
DAC Pin & $2 \times 8 \mathrm{Bit}$ \\
Çalışma Gerilimi & $2.2 \sim 3.6 \mathrm{~V}$ \\
WiFi & IEEE $802.11 \mathrm{~b} / \mathrm{g} / \mathrm{n}$ \\
Bluetooth & $4.2 \mathrm{BR} / \mathrm{EDR}+\mathrm{BLE}$ \\
SPI/I2C/UART & $4 / 2 / 3$ \\
CAN/Ethernet MAC & $1 / 1$ \\
Touch Sensor & 10 \\
Sicaklı Sensörü & Var \\
Manyetik Alan Sensörü & Var \\
\hline
\end{tabular}

IoT uygulamaları için ihtiyaç duyulan bir çok sensörü bünyesinde barındıran ESP32, dahili WiFi modülünün yanında bluetooth, RF ve IR gibi kablosuz haberleşme özelliklerine de sahiptir. Gerçek zamanlı uzaktan izleme ve kontrol sisteminde kullanılan DHT22, kapasitif nem ve termistör sıcaklık sensörü olmak üzere iki kısımdan meydana gelmektedir. DHT22 sıcaklık ve nem algılayıcı, kalibre edilmiş dijital sinyal çıkışı veren gelişmiş bir sensör birimidir. Üzerinde 8 bitlik mikrodenetleyici bulunmaktadır ve kısa tepki süresine sahiptir.

Sıcaklık ölçümünde $\pm 0.5{ }^{\circ} \mathrm{C}$ ve nem ölçümünde ise \pm $2 \% \mathrm{rH}$ bağll hata değerlerine sahiptir [24]. MCU'ya iletilen data; 16 bitlik nisbi nem, 16 bitlik sıcaklık ve 8 bitlik sağlama değeri olmak üzere 40 bitten oluşur.

Vcc ile data pinleri arasında 4.7 10 K arasında bir pull-up direnci bağlanmaktadır. Şekil 2'de DHT22 Sensörüne ait pin yapısı ve Tablo 2'de de teknik özellikleri görülmektedir.

DHT22'den gelen nem ve sicaklık bilgisini taşıyan sayısal sinyaller, mikrodenetleyiciler tarafından kolayca okunabilmektedir. Sicaklık ve nem değerini yüksek hassasiyetle ölçmesi ve açık kaynak kodu nedeniyle akıllı ev uygulamaları başta olmak üzere birçok uygulamada sıklıkla kullanılmaktadır.

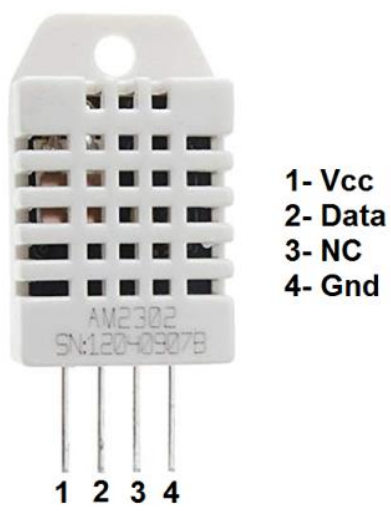

Şekil 2. DHT22 Sensörüne ait pin yapısı

Tablo 2. DHT22 Sıcaklık-Nem sensörü teknik özellikleri

\begin{tabular}{cc}
\hline Özellikler & Değer \\
\hline Çalışma Gerilimi & $3.3 \sim 6 \mathrm{~V}$ \\
Çıkış Sinyali & Dijital 1 bus \\
Ölçüm Aralığı & $0-100 \% \mathrm{RH},-40 \sim 80^{\circ} \mathrm{C}$ \\
Doğruluk & $\pm \% 2 \mathrm{RH},< \pm 0.5^{\circ} \mathrm{C}$ \\
Çözünürlük & $0.1 \% \mathrm{RH}, 0.1^{\circ} \mathrm{C}$ \\
Çalıșma Akım & $1-1.5 \mathrm{~mA}$ \\
\hline
\end{tabular}

Önerilen sistemde kullanılan ESP32 modül için gerekli yazılım Arduino IDE kullanılarak C dilinde yazılmıştır. Arduino IDE ile Arduino Uno, Leonardo, Mega ve Arduino Due gibi Atmel tabanlı kitler başta olmak üzere ESP32, ESP8266, STM32 ve Intel gibi farklı firmalara ait birçok denetleyici için de kod yazılmasını, yazılan kodların derlenmesini ve derlenen kodlarında denetleyicilere USB portu üzerinden yüklenmesini sağlayan bir platformdur. IoT uygulamalarında mobil cihazlar üzerinden kontrol çok yaygın hale gelmiştir. Android ve iOS cihazlar için uygulama geliştirmemizi sağlayan çok sayıda ücretsiz seçenek bulunmaktadır. $\mathrm{Bu}$ uygulamalardan birisi olan Blynk, Arduino, Raspery $\mathrm{Pi}, \mathrm{ESP}$, NodeMCU, chipKIT, Intel, LeMarker, Onion Omega, SparkFun, STM32 vb. gibi denetleyicilerin internet üzerinden kontrol edilmelerini sağlayan iOS ve Android uygulamaları için geliștirilmiş bir IoT platformdur. 

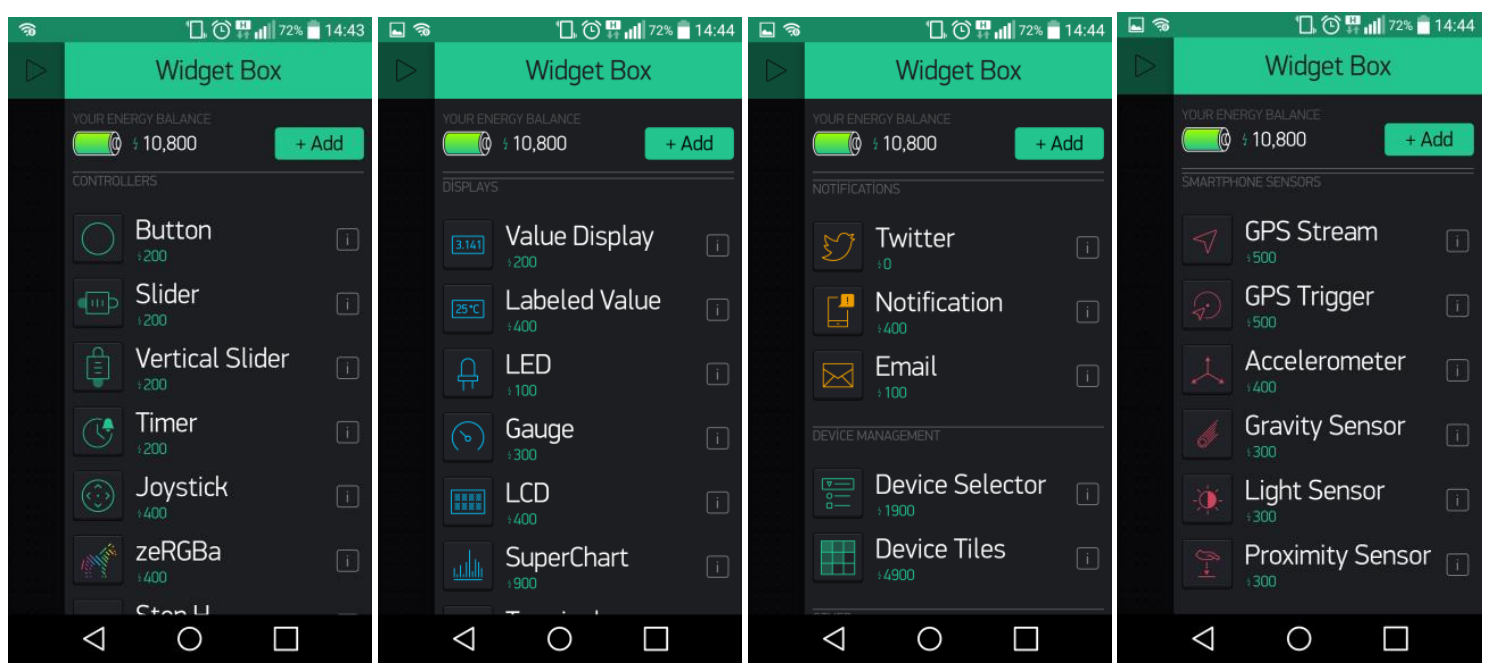

Şekil 3. Blynk Arayüz geliştiriciye ait Widget Box'lar.

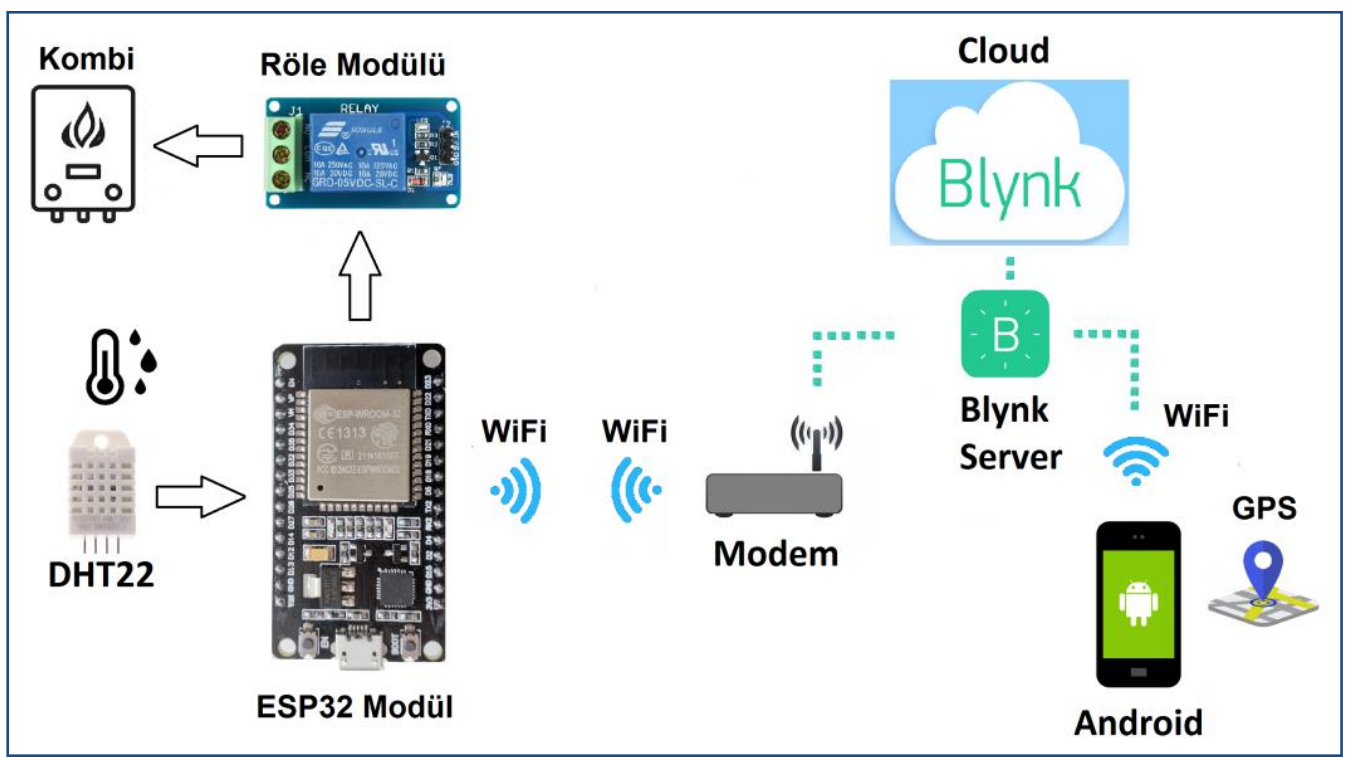

Şekil 4. Gerçekleştirilen Sistemin Yapısı

$\mathrm{Bu}$ platform sayesinde herhangi bir kod yazmaya gerek kalmadan, sadece Widgetleri kullanarak çok kısa sürede projeler için bir grafik arabirim geliştirilebilmektedir. Şekil 3'de Blynk'e ait bazı Widget Box'lar görülmektedir.

Bu Widget'ler; buton, led, slider, LCD, timer, display, joystick, bildirim, e-mail, twitter, GPS, ışık sensörü, yerçekimi sensörü, ivme sensörü ve yakınlık sensörü gibi özellikleri uygulamalara çok yönlü esneklik kazandırmaktadır. Blynk bulut hizmeti sayesinde sistemle ilgili sıcaklık, nem, akım, gerilim gibi sayısal veriler saklanır ve istenildiği zaman bulut server üzerinden e-mail yoluyla elde edilebilir. Birçok IoT uygulamasında ihtiyaç duyulan gerçek zaman saati Blynk widget özelliği ile kullanılabilmektedir. Zaman güncellemesi, bulunulan bölge saat dilimi seçilerek server tarafından otomatik olarak yapılmaktadır.

\section{Bulgular}

Akıllı ısıtma uygulamasına ait gerçekleştirilen sistemin genel yapısı Şekil 4'de görülmektedir. Sistem temel olarak sırasıyla; Wi-Fi üzerinden Blynk server ile haberleșebilen ESP32 modül, ortamın sıcaklık ve nem bilgisini ölçen DHT22 sensör, ısıtma sisteminin on-off kontrolünü sağlayan çıkış elemanı röle modülü, Blynk arayüz, Blynk server-bulut ve modem'den oluşmaktadır.

Gömülü WiFi modüle sahip ESP32 modülü DHT22'den aldığı sıcaklık ve nem verilerini her 10 sn'de Blynk server'a göndermektedir. DHT22'den gelen dijital bilginin okunması ve bu bilginin Blynk server'a gönderilmesi için sanal pinler kullanılmaktadır. Uygulamada nem verisinin gönderimi için V5, sıcaklık bilgisinin gönderimi içinde V6 sanal pinleri kullanılmıştır. Blynk uygulamasında, seçilen denetleyicilere ait tüm dijital ve analog pinlerin kullanılabilmesinin yanında, çok sayıda (0127) sanal pin de kullanılabilmektedir. Özellikle display, terminal, LCD ve gauge gibi widgetler, pratik bir kısıtlaması olmayan büyüklükte veri taşıyabilen sanal pinler yardımıyla kullanılmaktadır. Şekil 5a'da nem ve Şekil 5b'de sıcaklık verisini görüntüleyen gauge widgeti ayar penceresi görülmektedir. 


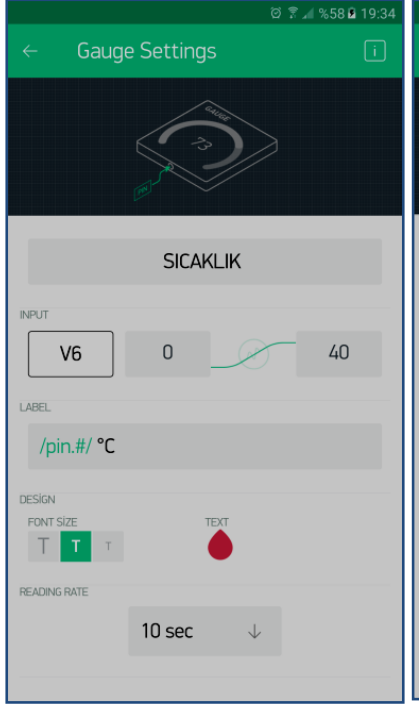

(a)

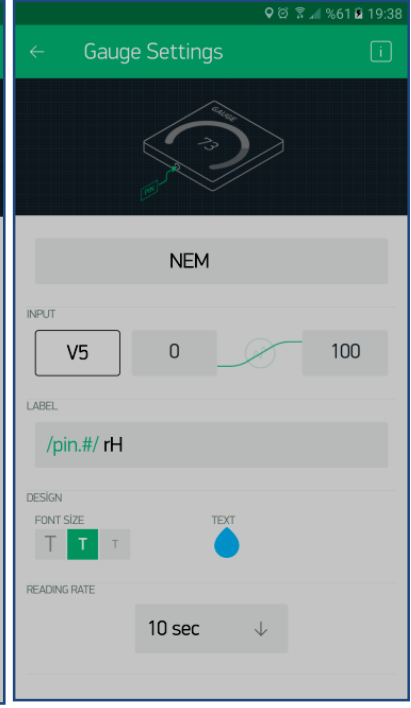

(b)

Şekil 5. Blynk uygulamasında (a) nem, (b) sıcaklık verisine ait gauge widget ayar penceresi.

Android cihaza kurulan "AKILLI EVIM" uygulaması sayesinde sistemle ilgili veriler server üzerinden periyodik olarak alınmaktadır. Bu android arayüz ile ESP32 arasındaki veri aktarımı çift yönlü olup, sıcaklık, nem, haftalık program, ayar sıcaklığı gibi sayısal veriler ve ayar parametreleri görüntülenebilmekte ayn zamanda da ayarlanabilmektedir.

Şekil 6.a'da uygulamaya ait gösterge paneli görülmektedir. Panelde ortama ait sicaklık, nem değerleri, ESP modülün WiFi sinyal seviyesi, mobil cihazın GSP konumu, twitter, e-mail, bildirim widgeti, sıcaklık ayarı, program ayarları, kombi durumu ve sıcaklık-nem grafiği bulunmaktadır. Şekil 6.b'de bildirim düzenleme penceresi görülmektedir. Sistemle ilgili sayısal değerlere ya da sanal pin değerlerine bağlı olaylar için bildirim oluşturmak mümkündür. Örnek olarak oluşturulan EVENT-1 de modüle ait WiFi sinyali \%30'un altına düștüğü durumda uygulama 2 ayrı bildirimi aktif hale getirir. Bunlardan ilki uygulama ekranı üzerinden yapılan bildirimdir. Diğeri ise uygulamaya önceden kaydedilen twitter hesabına gönderilen bildirimdir. Bu twitter hesabına gönderilen bildirim örneği Şekil 6.c'de verilmiştir. $\mathrm{Bu}$ şekilde farklı bildirim kanallarından kullanıcının önemli gördüğü olaylara ait istenilen sayıda bildirim oluşturmak mümkündür. EVENT-2 olarak olușturulan diğer bir bildirimde ortam sıcaklığının $27{ }^{\circ} \mathrm{C}$ 'nin üzerine çıması durumunda belirlenen e-mail adresine uygulama tarafından bildirim göndermektedir.

Akıllı ısıtma sisteminde mobil cihazından alınan GPS konum bilgisi kullanılarak ESP32 modül temeli kontrol sistemi ile olan mesafe anlı olarak "Haversine" formülü kullanılarak hesaplanmaktadır. Haversine formülü, yeryüzü üzerindeki herhangi iki noktaya ait enlem ve boylam değerlerini kullanarak noktalar arasındaki kuş-uçuşu mesafenin hesaplanmasını sağlar. Yeryüzü şekilleri ve ulaşım yollarının dikkate alınmadığ yönteminin $\% 0.3$ 'lük bir hesaplama hatası bulunmaktadır [25]. Eşitlik 1, 2 ve 3'de Haversine ait formüller verilmiștir.

$$
\begin{gathered}
a=\sin ^{2}\left(\frac{\varphi_{1}-\varphi_{2}}{2}\right)+\cos \varphi_{1} \cdot \cos \varphi_{2} \cdot \sin ^{2}\left(\frac{\lambda_{1}-\lambda_{2}}{2}\right) \\
c=2 \cdot \operatorname{atan}^{2}(\sqrt{a}, \sqrt{(1-a)}) \\
d=R \cdot c
\end{gathered}
$$

Burada; $\varphi 1$, başlangıç noktasının enlemi, $\varphi 2$, bitiş noktasının enlemi, $\lambda 1$, başlangıç noktasının boylamı, $\lambda 2$, bitiş noktasının boylamı, $d$, iki nokta arası mesafe $(\mathrm{km}), \mathrm{R}$, dünyanın yarıçapı'nı $(\mathrm{km})$ ifade etmektedir.

Haversine formülünün $\mathrm{C}$ koduna dönüştürülmüş hali Şekil 7'de görülmektedir. Formülde kullanılan dünya yarıçapı R= $6378.1 \mathrm{~km}$ olarak alınmıştır.

Kullanılan enlem ve boylam değerleri mobil uygulama tarafından elde edilen ve derece cinsinden değerlerdir. Haversine formülünde bu konum değerlerin radyan cinsinden kullanılması gerekmektedir. İki nokta arasındaki mesafeyi hesaplayan kod incelendiğinde başlangıç ve bitiş noktalarına ait enlem ve boylam değerlerinin radyan açı birimine dönüştürüldüğü görülmektedir. Hesaplama sonucunda iki nokta arası mesafe "km" cinsinden bulunmaktadır. Hesaplanan mesafe değeri ayarlanan değeri geçtiğinde kombinin tüketimini azaltmak için ısı değeri uygun değere otomatik olarak düşürülür. Eğer mesafe ayarlanan değerin altına düșerse bu durumda da ideal Isı konforunun en kısa sürede sağlanması için sıcaklık ayar değerleri otomatik olarak arttırılır.

\section{Tartıșma ve Sonuç}

İnternet teknolojisi üzerinden birçok hizmetin verildiği günümüzde, bu altyapıyı kullanan uygulamaların sayısı sürekli olarak artmaktadır. 


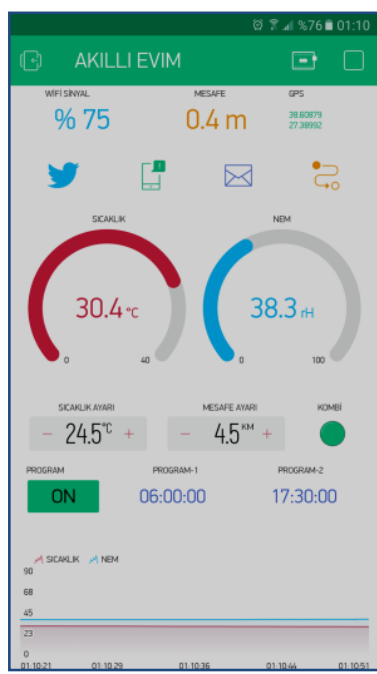

(a)

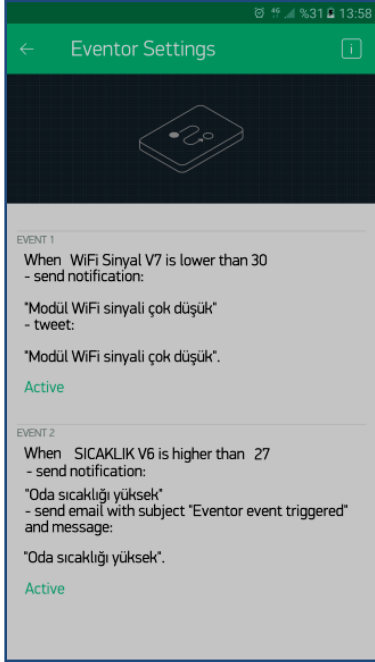

(b)

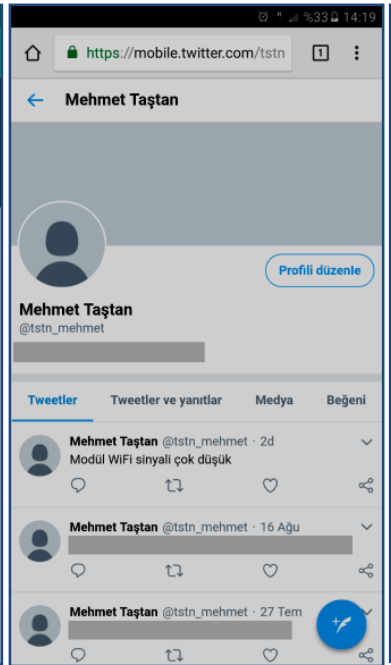

(c)

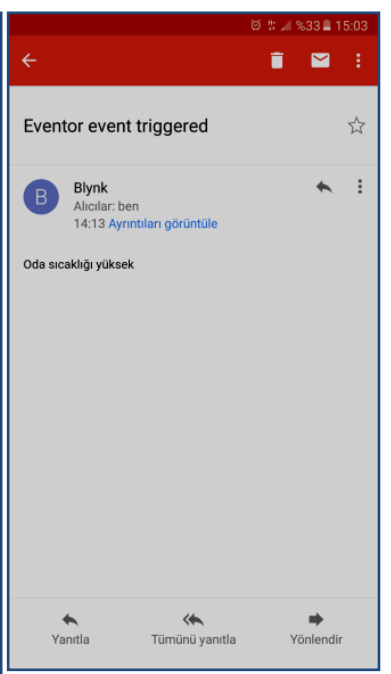

(d)

Şekil 6. (a) Blynk "AKILLI EVIM" gösterge paneli, (b) Olay ayarları (c) twitter bildirimi (d) e-mail bildirimi

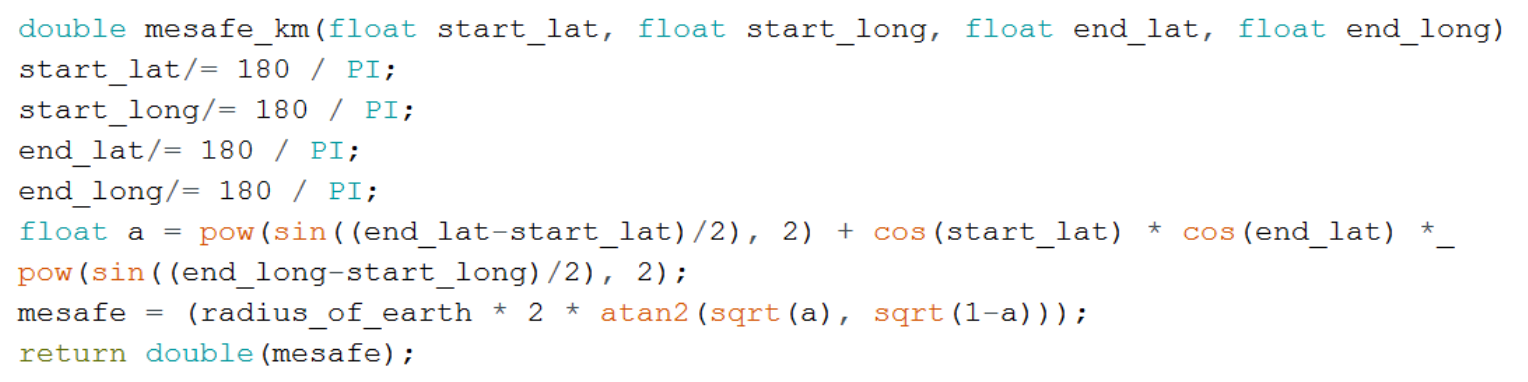

Şekil 7. Haversine formülün C kodu.

Alt yapısı internet olan IoT teknolojisi, insanların giderek artan konfor düşkünlügünü büyük ölçüde karşılamakta ve akıllı ve otonom cihazlara olan talebin de sürekli artmasına neden olmaktadır. Hayatımıza hızlı bir giriş yapan IoT kavramı, her geçen gün genişleyerek farklı sektör ve uygulamaları bünyesine dahil etmektedir.

$\mathrm{Bu}$ çalışmada IoT tabanlı yeni nesil ESP32 modül kullanarak akıllı ev uygulamalarına örnek bir akıllı ısıtma sistemi önerilmiştir. Blynk android arayüz geliştiricisi tarafından oluşturulan kullanıcı arayüzü, mobil cihazlar üzerinden isitma sistemine uzaktan erişim, kontrol ve izleme imkanı sunmaktadır. Akıllı ısıtma sistemi oda set sicaklığının yanında GPS konum bilgisinden hesapladığı mesafe değerine göre çalışma durumunu otomatik olarak ayarlamaktadır. Blynk bulut hizmeti sayesinde sicaklık ve nem gibi sayısal değerlerin zamana bağlı değişimleri sürekli olarak kaydedilmekte, istendiği zaman e-mail adresine server tarafından gönderilmektedir. Akıllı ısıtma sistemi düşük sıcaklık, yüksek sıcaklık, modül WiFi sinyal seviyesi, yüksek nem seviyesi, ısıtma sisteminin on-off durumları gibi birçok çalışma parametresini kullanıcılara twitter, e-mail ve kullanıcı ekranı üzerinden bildiri olarak gönderebilmektedir. Geliştirilen bu akıllı ısıtma sistemi enerji tüketimini azaltmanın yanında kullanıcılara isı ve kullanım konforu da sağlamaktadır.

\section{Kaynakça}

[1] Bröring, A., Schmid, S., Schindhelm, C. K., Khelil, A., Kabisch, S., Kramer, D., López, E. 2017. Enabling IoT ecosystems through platform interoperability. IEEE software, 34(1), 54-61.

[2] Shah, J., Mishra, B., 2016. Customized IoT enabled wireless sensing and monitoring platform for smart buildings. Procedia Technology, 23, pp.256-263.

[3] Gupta, R., Singh, K. K. 2018. IOT Door Monitoring System using Android Application. Trends in Opto-Electro and Optical Communications, 7(3), 21-24.

[4] Mahindar, R., Prakash, M., Ghosh, S., Mukherjee, S., Ghosh, R. 2018. IoT-based Home Appliances Control System Using NodeMCU and Blynk Server, 6(5), 16-22.

[5] Bohora, B., Maharjan, S., Shrestha, B. R. 2016. IoT Based Smart Home Using Blynk Framework. Zerone Scholar, 1(1), 26-30.

[6] Evans, D., 2011. The internet of things: How the next evolution of the internet is changing everything. CISCO white paper, 1(2011), 1-11.

[7] Gökozan, H., Taştan, M., Sarı, A., 2017. Smart Cities and Management Strategies. Gokbunar A. R., Virlanuta F. O., Zungun, D. (Ed.) 2017 Socio- 
Economic Strategies içinde (115-123), LAMBERT Academic Publishing, 244s,

[8] Lynggaard, P., Skouby, K. E. 2016. Complex IoT Systems as Enablers for Smart Homes in a Smart City Vision. Sensors, 16(11), 1840.

[9] Calvillo, C. F., Sánchez-Miralles, A., Villar, J. 2016. Energy management and planning in smart cities. Renewable and Sustainable Energy Reviews, 55, 273-287.

[10] Harper, R. (Ed.). 2006. Inside the smart home. Springer Science \& Business Media.

[11] Stojkoska, B. L. R., Trivodaliev, K. V. 2017. A review of Internet of Things for smart home: Challenges and solutions. Journal of Cleaner Production, 140, 1454-1464.

[12] Taştan, M., Gökozan, H. 2018. An Internet of Things Based Air Conditioning and Lighting Control System for Smart Home. American Scientific Research Journal for Engineering, Technology, and Sciences (ASRJETS), 50(1), 181189.

[13] Kulkarni, A., Mukhopadhyay, D. 2018. Internet of Things Based Weather Forecast Monitoring System. Indonesian Journal of Electrical Engineering and Computer Science, 9(3), 555557.

[14] Marinakis, V., Doukas, H. 2018. An Advanced IoT-based System for Intelligent Energy Management in Buildings. Sensors, 18(2), 610.

[15] Kamienski, C., Soininen, J.P., Taumberger, M., Dantas, R., Toscano, A., Salmon Cinotti, T., Filev Maia, R., Torre Neto, A., 2019. Smart water management platform: Iot-based precision irrigation for agriculture. Sensors, 19(2), 276.

[16] Taştan, M. 2018. IoT Based Wearable Smart Health Monitoring System. Celal Bayar University Journal of Science, 14(3), 343-350.
[17] Öcal, H., Doğru, İ. A., Barış̧̧ı, N. 2019. Akıllı ve Geleneksel Giyilebilir Sağlı Cihazlarında Nesnelerin İnterneti. Politeknik Dergisi, 22(3), 695-714

[18] Çaylı, A., Akyüz, A., Baytorun, A. N., Boyacı, S., Üstün, S., Kozak, F. B. 2017. Sera Çevre Koşullarının IOT Tabanlı İzleme ve Analiz Sistemiyle Kontrolü. Türk Tarım-Gıda Bilimi ve Teknolojisi Dergisi, 5(11), 1279-1289.

[19] Gökozan, H., Taştan, M., Sarı, A. 2017. Akıllı Şehirler ve Yönetim Stratejileri, II. Uluslararası Stratejik Araştırmalar Kongresi, Antalya, TÜRKIYE

[20] Shafiee, S., Topal, E. 2009. When will fossil fuel reserves be diminished?, Energy policy, 37(1), 181-189.

[21] Ahmad, M. W., Mourshed, M., Yuce, B., Rezgui, Y. 2016. Computational intelligence techniques for HVAC systems: A review. Building Simulation 9(4), 359-398.

[22] Iqbal, S., Khan, S., Malik, A., Ahmad, I., Javaid, N. 2018. IoT Operating System Based Fuzzy Inference System for Home Energy Management System in Smart Buildings. Sensors, 18(9), 2802.

[23] Espressif, 2018. ESP32, [Son Erişim: 31.08.2018] https://www.espressif.com/en/products/hard ware/esp32/overview

[24] Aosong Electronics, 2010. Digital-output relative humidity \& temperature sensor/modüle, [Son Erişim: 16.08.2018] https://www.sparkfun.com/datasheets/Sensors /Temperature/DHT22.pdf

[25] Movable Type Scripts, 2018. Calculate distance, bearing and more between Latitude/Longitude points, [Son Erişim: 04.09.2018] https://www.movabletype.co.uk/scripts/latlong.html 